\title{
"Darlo todo": sacrificio, profesión y maternidad de bailarinas de tango y contemporáneo en Buenos Aires
}

\section{Artículo de investigación}

Juliana Verdenelli

Universidad Nacional de La Plata. Escuela

Interdisciplinaria de Altos Estudios Sociales.

Universidad Nacional de San Martín, Argentina

(IdIHCS/UNLP-IDAES/UNSAM)

juliverdenelli@gmail.com

Recibido: 24 de agosto de 2021

Aceptado: 9 de octubre de 2021

Como citar este artículo: Verdenelli, J. (2022). “Darlo todo": sacrificio, profesión y maternidad de bailarinas de tango y contemporáneo en Buenos Aires. Calle14: revista de investigación en el campo del arte. 17(31), pp. 98-113. DOI: https://doi.org/10.14483/21450706.18701

\section{(c) (1)}

https://creativecommons.org/licenses/by/4.0/deed.es 


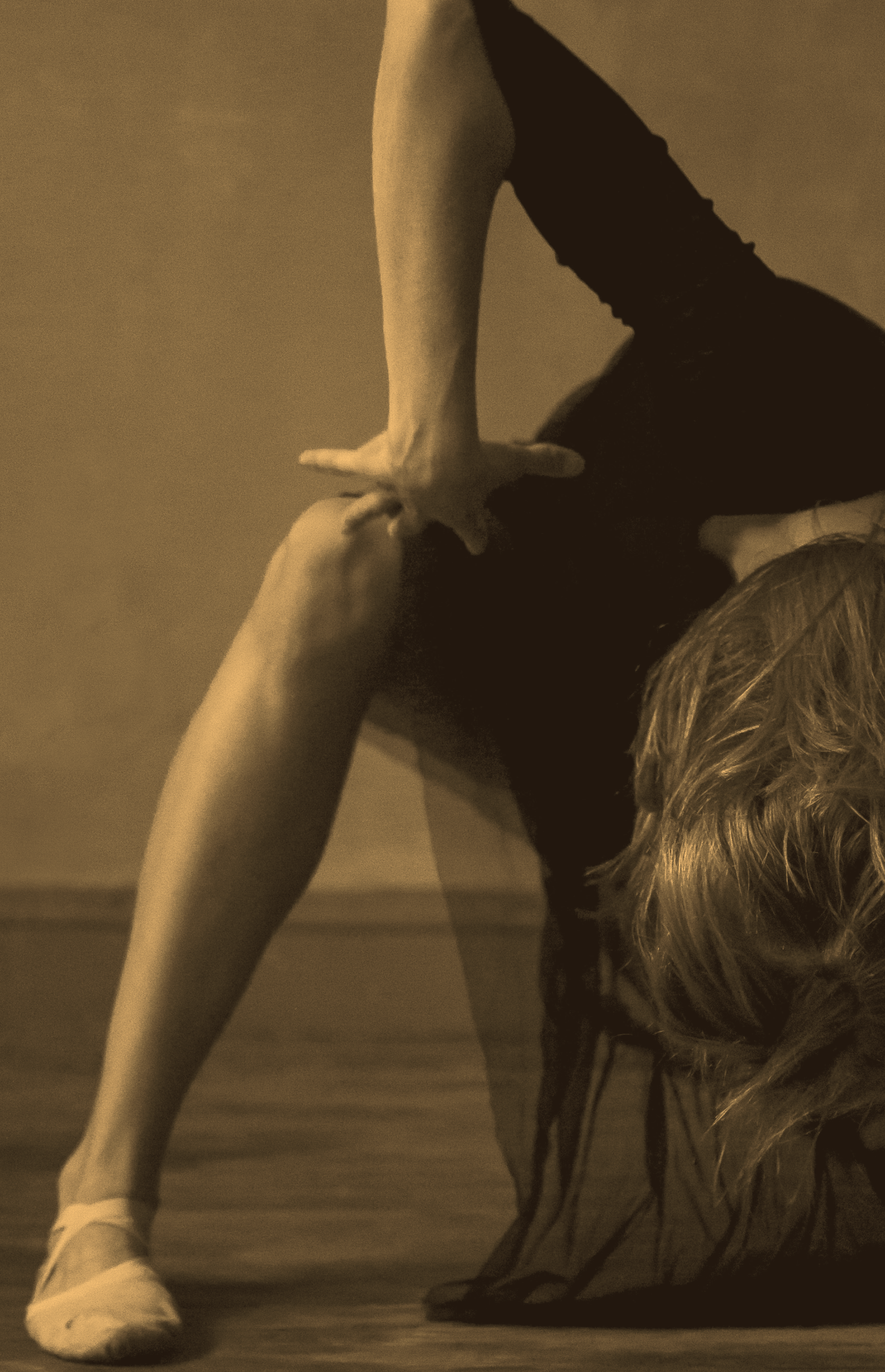


"Darlo todo": Sacrificio, profesión y maternidad de bailarinas de tango y contemporáneo

en Buenos Aires

\title{
Resumen
}

En este artículo se indaga la relevancia de la noción de sacrificio para comprender ciertas desigualdades persistentes en las relaciones de género en los circuitos dancísticos profesionales del tango y la danza contemporánea en Buenos Aires. A partir de los datos recolectados en un trabajo de campo etnográfico realizado entre 2014 y 2020 con un grupo de bailarinas madres, se observa que las representaciones del sacrificio son centrales para comprender los repertorios discursivos que son movilizados para reivindicar un compromiso total e intensivo con el rol de bailarina y para postular una incompatibilidad inherente a la carrera dancística con la maternidad. Se concluye que este ideal de sacrificio y consagración provoca sensaciones de desajuste e incompatibilidad dentro de los proyectos personales de muchas artistas de cara a la conciliación de la profesión y la maternidad.

\section{Palabras clave}

Balance profesión-maternidad; danza contemporánea; sacrificio; tango

"Give it all": Sacrifice, profession and motherhood in dancers of tango and contemporary dance in Buenos Aires

\begin{abstract}
This article investigates the relevance of the notion of sacrifice to understand certain persistent inequalities in gender relations within the professional tango and contemporary dance circuits of Buenos Aires. From the data collected in an ethnographic fieldwork carried out between 2014 and 2020 with a group of dancers who are mothers, the representations of sacrifice are central to understanding the discursive repertoires that are mobilized to claim a total and intensive commitment to the role of dancer and to postulate an incompatibility inherent between a dance career and motherhood. It is concluded that this ideal of sacrifice and consecration causes feelings of mismatch and incompatibility within the personal projects of many artists regarding the reconciliation of career and motherhood.
\end{abstract}

\section{Keywords}

Career-motherhood balance; contemporary dance; sacrifice; tango

« Tout donner »: Sacrifice, métier et maternité chez les danseurs de tango et de danse contemporaine à Buenos Aires

\section{Résumé}

Cet article interroge la pertinence de la notion de sacrifice pour comprendre certaines inégalités persistantes dans les relations de genre dans les circuits professionnels du tango et de la danse contemporaine à Buenos Aires. À partir des données recueillies dans un travail de terrain ethnographique réalisé entre 2014 et 2020 auprès d'un groupe de danseuses mères, les représentations du sacrifice sont centrales pour comprendre les répertoires discursifs qui sont mobilisés pour revendiquer un engagement total et intensif dans le rôle de danseuse et postuler une incompatibilité inhérente entre carrière de danseuse et maternité. Il est conclu que cet idéal de sacrifice et de consécration provoque des sentiments d'inadéquation et d'incompatibilité au sein des projets personnels de nombreux artistes concernant la réconciliation de la profession et de la maternité.

\section{Mots clés}

Équilibre profession-maternité ; danse contemporaine ; sacrifice ; tango 
"Dar tudo": sacrifício, profissão e maternidade de bailarinas de tango e contemporâneo

em Buenos Aires

\section{Resumo}

Neste artigo se indaga a relevância da noção de sacrifício para compreender certas desigualdades persistentes nas relações de gênero nos circuitos profissionais de tango e dança contemporânea em Buenos Aires. A partir de dados coletados em um trabalho de campo etnográfico realizado entre 2014 e 2020 com um grupo de bailarinas mães, se observa que as representações do sacrifício são centrais para compreender os repertórios discursivos que são mobilizados para reivindicar um compromisso total e intensivo com a função de bailarina e para postular uma incompatibilidade inerente a carreira de dança com a maternidade. Se conclui que este ideal de sacrifício e consagração provoca sensações de desajuste e incompatibilidade dentro dos projetos pessoais de muitas artistas em relação com a conciliação profissãomaternidade.

\section{Palavras chave}

Equilíbrio profissão-maternidade; Dança Contemporânea; Sacrifício; Tango

Tukui rurai sugkuna takispa Achka iachaikuska wambra iukaspa mulluri tunai tango suti Buenos Aires sutipi

\section{Maillallachiska}

Kai kilkaipi tapuchiku imasami sakinkuna sugsinama sug rurai kunata kaita katichingapa, chi nispa tiami llapa llakisina mana paikuna allila apachinkuna kai mulluri tango suti, chi nispa kai tapuchikuna kauaspa ullaspa, kai watakunapi, 2014. I 2020 kaura, sug warmikunamipudirruskuna kawankuna llakirispa. Sug warmikuna Munanaku katichinga kai mulluri, llakinaku paipawambrakunata, sakingapa chasallata iuiarinaku imasami rurangakuna mana ñipita sapalla, sakingapa kankuna achaka iachakuan chasallata wambra llukagkuna.

\section{Rimangapa Ministidukuna}

Apachiskata kawai; iachai wambra llukai; Nugpata mullurii; sug ruraikunata sakii; tunai chasa suti 


\section{Introducción}

El 13 de septiembre de 2017 se estrenó la miniserie argentina $E l$ maestro ${ }^{1}$. En esta ficción de doce episodios Julio Chávez interpreta a Abel Prat, un ex bailarín de danza clásica que supo ser una estrella internacional. Retirado de los escenarios hace casi tres décadas, Prat se dedica a dar clases en una escuela barrial de Buenos Aires. Es un maestro estricto e inflexible: considera que el esfuerzo, la disciplina, la dedicación y la autoexigencia son los pilares fundamentales para construir una carrera promisoria en la danza.

Luisa Galarza -interpretada por la actriz Carla Quevedo- es una joven de sectores populares que tiene mucho talento para la danza y que desea formarse con el legendario bailarín para poder ganar una beca de formación en Canadá. Prat establece una relación de mentor-discípula con Luisa que, poco a poco, se va entremezclando con una relación amorosa entre ambos. En medio de todo este proceso, ella queda accidentalmente embarazada de su novio boxeador. Pone en riesgo su futuro como bailarina hasta que sufre un aborto espontáneo, que la libera de tener que tomar una decisión.

Por su parte, la villana de la serie es Paulina Bravo interpretada por Inés Estévez-, otra maestra de danza clásica; actual rival y ex pareja amorosa y partenaire de Prat. Esta mujer vive llena de rencor y frustración porque tuvo que resignar su carrera cuando quedó embarazada de él. Si bien ambos habían decidido continuar con el embarazo y tener al hijo en común, lo cierto es que mientras él triunfaba en los principales escenarios del mundo, ella arruinaba su futuro como bailarina.

Esta representación del embarazo como la ruina profesional no es exclusiva de la danza clásica y se repite, con variaciones, en los dos circuitos dancísticos en los que se realizó mi investigación doctoral sobre los balances entre la profesión y la maternidad de bailarinas de tango y bailarinas de contemporáneo en la ciudad de Buenos Aires (Verdenelli, 2020). En el marco de este estudio, entre 2013 y 2020 me dediqué a "seguir" etnográficamente a un grupo de bailarinas madres — todas ellas heterosexuales, blancas, cisgénero, jóvenes y de mediana edad y de sectores medios urbanos- en sus actividades cotidianas, con el objetivo de describir y

1 Co-producida por Pol-ka Producciones, Turner Broadcasting System, Eltrece y Cablevisión. El guion fue escrito por Romina Paula y Gonzalo Demaría. La dirección fue de Daniel Barone. analizar sus experiencias situadas de maternidad en relación con sus trayectorias artísticas.

A partir de la categoría propuesta por Mariana Sáez (2017) de práctica corporal artística, consideré que la cuestión de lo corporal en vinculación con lo artístico convertía a la danza en un terreno privilegiado para indagar sobre los conflictos, las tensiones o las disputas que enfrentan las mujeres que desean conciliar sus maternidades con sus carreras artísticas. De igual forma, decidí hacer foco en las experiencias de maternidad que resultan de una transformación corporal temporal asociada a la gestación, que es exteriormente perceptible y socialmente significada, e indagar sobre los modos en que los cambios fisiológicos que tienen lugar durante la gestación, el parto y el puerperio se impregnan de sentido y adquieren un carácter de cambio social (Imaz, 2010).

Lejos de pensar a la maternidad como un destino de las mujeres, o como su única forma de realización en el mundo social cuando es una opción elegida —es decir, cuando se ubica dentro de sus deseos y proyectos construidos culturalmente-, el eje de mi análisis se ubicó en las posibilidades que encuentran las mujeres que desean ensamblar su rol como madres con su rol como bailarinas dentro de un mismo proyecto personal.

Específicamente, en este artículo me pregunto por la relevancia de la noción de sacrificio para comprender los repertorios discursivos que son movilizados dentro de los circuitos dancísticos profesionales del tango y la danza contemporánea para reivindicar un compromiso total e intensivo con el rol de bailarina y que construyen la idea de que existe una incompatibilidad inherente a la carrera dancística con la maternidad.

Para ello, en una primera instancia me detengo en los aportes específicos de los diferentes estudios relevados que problematizan los sentidos sobre la maternidad en la danza profesional y que dan cuenta de la invisibilización de las experiencias maternas de las bailarinas profesionales, con la clara intención de contribuir a la construcción de conocimiento sobre el fenómeno en cuestión.

Luego, indago cuáles son los repertorios discursivos sobre el sacrificio que son movilizados dentro de los circuitos dancísticos del tango y del contemporáneo para reivindicar un compromiso total e intensivo con el rol de bailarina y que refuerzan el ideal de consagración - de la madre y de la artista - a partir de nociones como sacrificio, entrega o renuncia personal. 


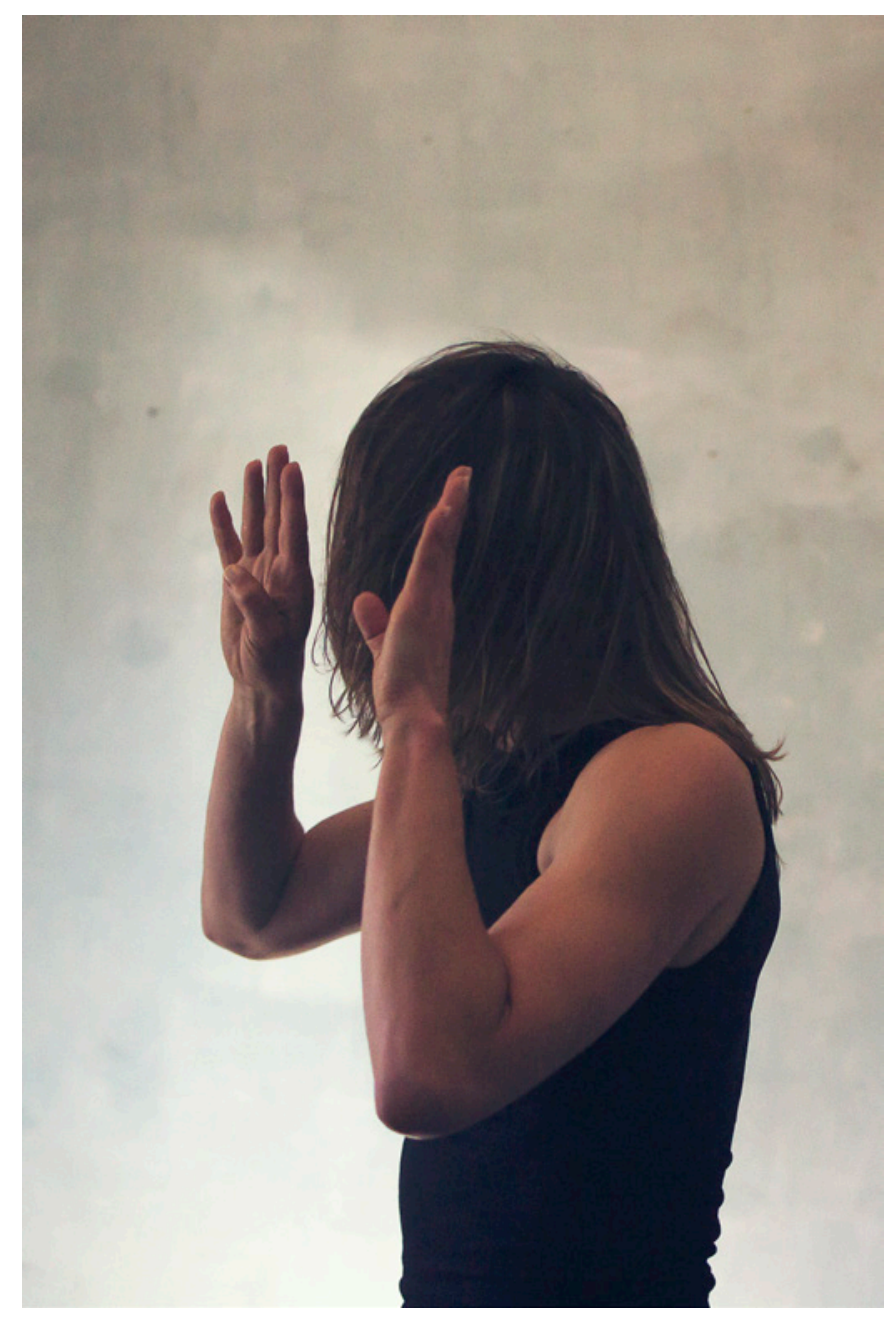

Imagen 1. Sofía Pascualetti (2020). ¿Para qué bailo?

\section{Danza y maternidad}

Históricamente, la mayoría de las mujeres que dejaron su impronta creativa en la danza occidental no tuvieron hijos. Desde grandes íconos como Anna Pávlova (1881-1931) o Ninette de Valois (1898-2001)² hasta la actualidad, ciertos mandatos de género perduran -con escasas variaciones - en el mundo del ballet. Uno de ellos, probablemente el más elemental, es que el matrimonio, el embarazo y el éxito artístico no se mezclan (Morris, 2015).

La famosa bailarina rusa Anna Pávlova, por ejemplo, solía decir que sin sacrificio - y sin la capacidad de someterse a una estricta disciplina - era imposible triunfar en el mundo del ballet. Afirmaba que para una

2 Anna Pávlova fue una famosa bailarina rusa del siglo XX que se convirtió en el arquetipo de la bailarina de danza clásica: delgada, de apariencia delicada y etérea, dispuesta a consagrarse por completo a su vocación. Por su parte, Ninette de Valois también fue una reconocida bailarina de ballet y una prestigiosa coreógrafa irlandesa, además de la fundadora y directora del Royal Ballet del Reino Unido. bailarina era elemental entregarse por completo a su arte y que, para poder trascender, debía encontrar la manera de transformar el amor en algo espiritual. Se trataba de convertir al amor en una especie de inspiración divina, de sublimarlo en el movimiento para lograr conmover al público.

Según Geraldine Morris (2015), fue justamente esta capacidad de renunciar a todo lo demás y de sacrificarse por el arte lo que colocó a Pávlova en un lugar central dentro de la historia de la danza clásica. Así, se convirtió en una especie de heroína legendaria y encarnó, en su propia figura, el modelo de bailarina ideal: una belleza etérea, capaz de revelar el espíritu a través de la materia ${ }^{3}$.

Susan Crow (2002), ex bailarina y coreógrafa del Royal Ballet fundado por de Valois, recuerda que, en su época

$3 \quad$ Eugenia Cardús (2015) analiza la figura femenina del ballet y su ideal de belleza unida a una concepción moral de ascetismo y celibato, a una visión cristiana del mundo que es simbolizada en un cuerpo femenino virginal, pálido, trágico, poético y perturbado. 
como bailarina de la compañía, el matrimonio era considerado una "sentencia de muerte" para la carrera de cualquier mujer. En cambio, afirma que para los bailarines varones casarse era algo aceptable e, incluso, deseable y que el matrimonio les otorgaba mayor prestigio y respeto dentro de la compañía. En cuanto a la combinación entre baile y maternidad, la coreógrafa no duda en sentenciar: "era algo absolutamente impensable".

De manera similar, en una mesa redonda organizada por Dance Umbrella y Dance UK en el año 2009, otra ex bailarina del Royal Ballet, Lynn Seymour, contó que en el año 1965 decidió abortar ante el dilema de tener un hijo o estrenar la obra Romeo y Julieta. Poco tiempo después, su rol protagónico en esta obra la posicionaría como una de las principales bailarinas de su generación.

Esta problemática no es exclusiva del mundo del ballet. Marina Abramovic ${ }^{4}$, por ejemplo, es otra famosa artista y performer serbia que suele ser muy contundente al opinar sobre la imposibilidad de conciliar la carrera artística con la maternidad. En una entrevista otorgada a un diario español en 2014, decía:

Las mujeres no están tan preparadas para sacrificarse por el arte como los hombres. Las mujeres quieren tener familia e hijos y además dedicarse al arte. Pero, siento decirlo, eso no es posible. Tenemos un cuerpo y para ser artista hay que consagrarlo a ello por completo. El arte exige el sacrificio de todo, incluida la vida normal. (Marina Abramovic. Málaga hoy, diciembre 2014).

Para esta bailarina, una buena artista debe consagrarse por completo al proceso creativo y esto implica, entre otras cuestiones, renunciar a la posibilidad de tener hijos. En otra entrevista realizada en agosto de 2016 para un medio alemán, Abramovic contó que se practicó tres abortos a lo largo de su vida y que siempre supo que "los hijos serían un desastre" para su trabajo. Afirma que las artistas cuentan con una energía limitada en el cuerpo y que, al tener hijos, se ven obligadas a dividirla. La renuncia a las ataduras de la vida normal es el precio que hay que pagar si se desea obtener a cambio la libertad creativa. Para ella, esa es la razón por la que las mujeres no son tan exitosas como los hombres en el mundo del arte: no están dispuestas

$4 \quad$ La artista de 74 años visitó la Argentina durante la inauguración de la Bienal de Performance 2015, que se desarrolló en el Centro de Arte Experimental de la UNSAM en Buenos Aires. a sacrificar todo lo demás —ocio, vida social, pareja, familia, hijos- por alcanzar la cima de su carrera.

A partir de estos ejemplos, podría pensarse que para algunas bailarinas la decisión de no tener hijos se basó en la idea de que existe una incompatibilidad inherente a la profesión con la maternidad ${ }^{5}$. Al observar los testimonios de aquellas mujeres que decidieron convertirse en madres en el trascurso de su carrera, esta hipótesis cobra aún más sentido ${ }^{6}$. Estas artistas suelen destacar las múltiples dificultades que enfrentaron al tratar de conciliar su carrera artística y su vida familiar. Por ejemplo, en su autobiografía Push Comes to Shove (1992), la coreógrafa Twyla Tharp cuenta que en muchas ocasiones se sintió obligada a abandonar el cuidado de su hijo pequeño para poder desarrollar plenamente su carrera como coreógrafa.

Bronislava Nijinska y Birgit Cullberg también fueron madres, a la vez que grandes mentoras y reconocidas coreógrafas, y debieron atravesar dilemas constantes entre las demandas de la maternidad y las necesidades de su profesión, aparentemente opuestas e incompatibles (Abad Carlés, 2012). Igualmente, la ya mencionada Susan Crow (2002) se refiere a su lucha personal por

$5 \quad$ Claro que también son muchas las bailarinas que deciden no tener hijos por otros muchos motivos y que se ven obligadas a defender públicamente su derecho a no ser madres, teniendo que explicar y justificar esta decisión personal, una y otra vez, frente a una sociedad que las continúa viendo como mujeres carentes de algo Un ejemplo popular es el caso de Paloma Herrera, ex primera bailarina y actual directora del ballet estable del Teatro Colón en Buenos Aires. Ella se define como una mujer "anti-mandatos" y dice que nunca deseó casarse ni tener hijos. En esa misma entrevista, reconoce que puede sonar "raro", "egoísta" o "poco convencional", pero afirma que nunca le interesó ser madre, que siempre valoró su libertad y la falta de otras responsabilidades por sobre todas las cosas. (Revista Para ti 15 de octubre de 2017).

[ Link: https://www.infobae.com/parati/news/2017/10/15/paloma-herrera-no-me-tienta-la-maternidad/ ]

$6 \quad$ Una excepción esta constituida por la historia de Isadora Duncan (1878-1927), una de las creadoras de la danza moderna. Esta mujer rompió con todos los cánones estéticos de la danza clásica y se negó a usar las zapatillas de baile. No dudó en convertirse en madre soltera, algo muy inusual para su época. También fue una pionera en salir al escenario y bailar embarazada, afirmando que la maternidad era parte de su vida creativa. Sin embargo, su experiencia materna tendría un final trágico cuando sus dos pequeños hijos, Deirdre y Patrick, se ahogaron con su niñera en un accidente automovilístico en el río Sena, en París, mientras Duncan se encontraba trabajando como coreógrafa.

Por otro lado, Ana Abad Carlés (2012) destaca la paradoja de que, si bien en el escenario Duncan exhibía orgullosa su maternidad, dentro de la sociedad de su tiempo esta imagen maternal quedaría restringida a la de ser "mentora" de sus hijos artísticos: una madre virgen y una maternidad concebida artísticamente, más que sexualmente. 
tratar de equilibrar sus múltiples roles como maestra, coreógrafa y madre. De nuevo, otra ex primera bailarina del Royal Ballet y madre de dos hijos, Antoinette Sibley (Clarke, 1981), reflexiona sobre su propia historia y afirma que para una bailarina es muy difícil decidir ser madre.

En un artículo sobre las representaciones de las bailarinas en el cine, Morris (2015) observa que en todas las películas las protagonistas femeninas se ven obligadas a elegir entre el amor y la danza -o en el caso de El cisne negro, entre el éxito y la castidad-. Dice que en estos argumentos se refuerza la idea de que existe una incompatibilidad inherente a la profesión con la vida familiar e incluso, con la vida personal en general. A la vez, se reproduce un modelo de artista mujer que debe sacrificarlo todo - hasta la vida misma, en el caso del cisne negro- por alcanzar el éxito y el reconocimiento del público.

Eugenia Cardús (2015), por su parte, se pregunta por la representación de la bailarina como una mujer trabajadora en Argentina durante el primer peronismo y analiza la película Mujeres que bailan (1949), dirigida por Manuel Romero y protagonizada por Fanny Navarro y Niní Marshall. Allí la protagonista es una mujer joven que desafía el mandato de la vida doméstica y que considera que su única opción es trabajar bailando. En este relato fílmico, la vida afectiva de la protagonista es puesta siempre en tensión con la carrera profesional: hay que elegir entre un marido o el escenario. Al elegir una carrera en la danza, se inician una serie de desgracias para la protagonista que terminan con el castigo al cabaret y con ella bailando can-can frente a marineros borrachos que intentan abusarla.

Por otro lado, Ana Abad Carlés (2012) analiza que la paulatina desaparición de las mujeres coreógrafas en la danza occidental suele explicarse a partir de argumentaciones que apelan a tres tipos de determinismos: el biológico, el emocional y el espacial. Me detendré aquí en el determinismo biológico, a partir del que se argumenta que las mujeres abandonan sus carreras profesionales para convertirse en madres y formar una familia. Según estos testimonios, la mayoría de las bailarinas finalizan sus carreras alrededor de los treinta años, momento vital en el que opera cierta presión biológica en aquellas que desean tener hijos y que también suele coincidir con el momento en que se inician las carreras coreográficas.

Abad Carlés cuestiona este argumento y sostiene que reducir la desaparición de las mujeres de un ámbito creativo en el que en el pasado han tenido un gran protagonismo a la maternidad es una justificación fácil y necesariamente parcial. También destaca que, a diferencia de otros ámbitos laborales, el de la danza se ha movido desde sus inicios en esferas mayormente femeninas y, a su entender, esto constituye una razón de peso para esperar que en este ámbito se hubiera desarrollado una mayor adecuación del entorno y de las dinámicas laborales hacia sus protagonistas mujeres.

Para Abad Carlés es la falta de adecuación de las transiciones profesionales y de las condiciones de trabajo la que dificulta la incorporación de las mujeres a la carrera coreográfica y no la maternidad en sí misma. En este sentido, también destaca la inexistencia de "rutas de retorno" para aquellas mujeres que, por diversos motivos -entre ellos, la maternidad-, se alejan temporalmente de la profesión, con excepción del ámbito educativo. El cuidar y el educar parecen ser términos claves para comprender los condicionantes de género en las carreras de las mujeres en la danza.

Esta autora también se pregunta por qué el ejemplo de las mujeres que fueron madres y que desarrollaron carreras artísticas exitosas ha sido invisibilizado para las futuras generaciones de artistas, que podrían estar interesadas en seguir esos mismos caminos. Dice que esta ausencia de modelos existentes o de narrativas ejemplares impide enmarcar la comprensión de las propias experiencias dentro de un proceso más amplio.

Por otro lado, Crow (2002) destaca la necesidad de un cambio en las reglas masculinas que rigen el mundo de la danza hasta la actualidad y toma como el inicio de un proceso de transformación el hecho de que la principal bailarina del Royal Ballet, Darcey Bussell, haya vuelto a subirse a los escenarios luego de dar a luz a su hija en el año 20017. Este proceso de transformación también puede verse actualmente en la escena local, en dónde la primera bailarina del Teatro Colón, Nadia Muzyca es, además, madre de dos niños pequeños.

Partiendo de estos aportes, durante mi etnografía pude identificar algunas de las particularidades que presenta la búsqueda por encontrar balances entre la maternidad y la profesión en bailarinas de tango y bailarinas de contemporáneo en Buenos Aires. Específicamente, observé las dificultades que estas mujeres

\footnotetext{
$7 \quad H o y$ sabemos que Bussell no continuaría bailando por mucho tiempo más: en el año 2004 tuvo a su segunda hija y en el año 2006 anunció su retiro.
} 


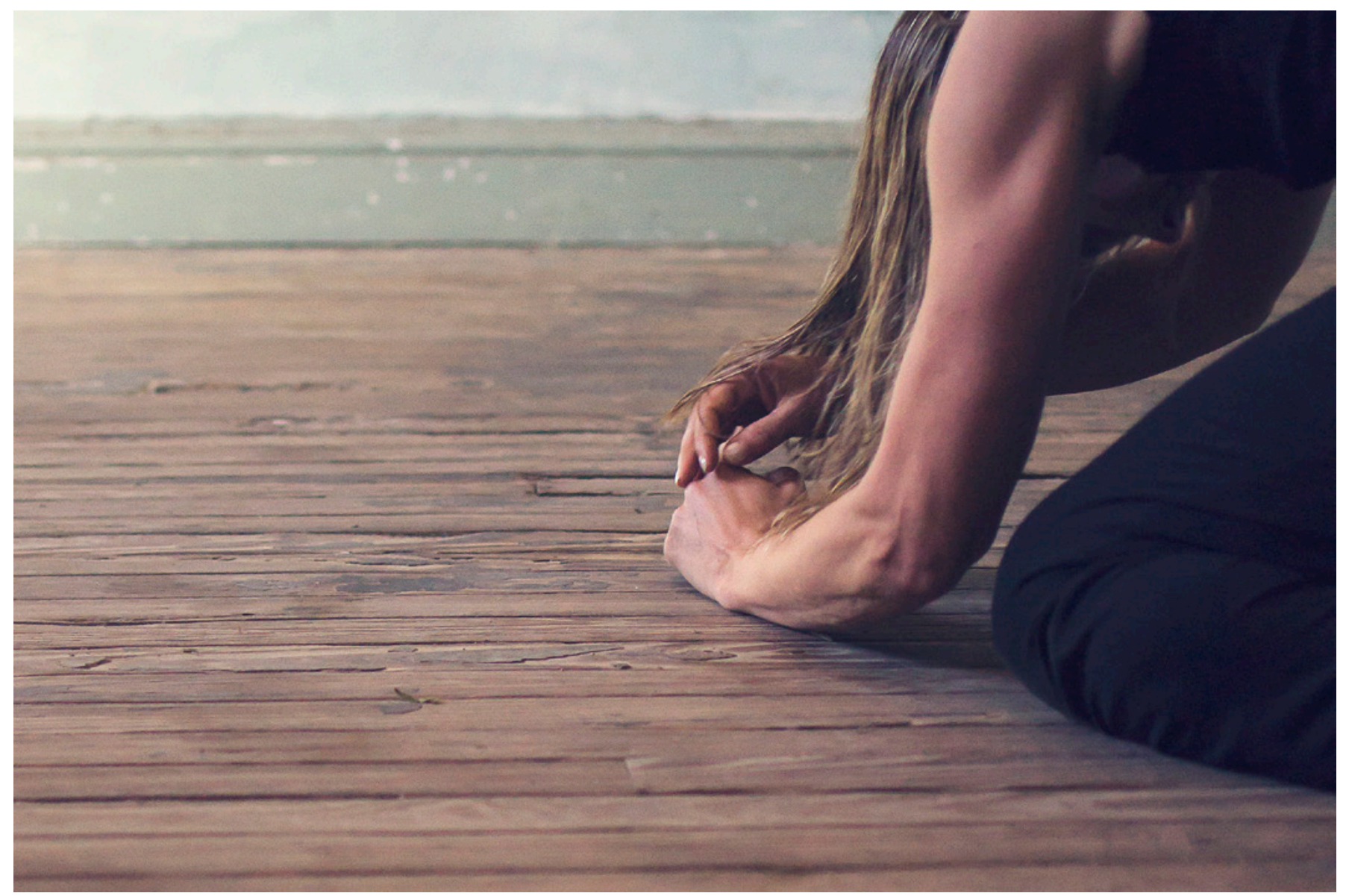

Imagen 2. Sofía Pascualetti (2020). ¿Para qué bailo?.

experimentan durante sus embarazos respecto a su concepción de cuerpo como instrumento de trabajo (Mora, 2011) y sus modos particulares de entenderlo, representarlo, moverlo y vivirlo. A su vez, atendí a las implicancias subjetivas que tiene para muchas artistas el hecho de negociar entre dos roles aparentemente incompatibles: ser madre y ser bailarina.

\section{El sacrificio}

Durante el trabajo de campo observé que la idea de sacrificar lo personal por la danza aparecía como una suerte de transformación moral que era capaz de construir el verdadero diferencial en la carrera de una bailarina de tango o de contemporáneo. Los relatos sobre los procesos de formación solían destacar el esfuerzo, la entrega, la dedicación, la consagración, el entrenamiento riguroso, la autoexigencia y la renuncia a otros aspectos de la vida normal u ordinaria, principalmente al tiempo de ocio o al tiempo compartido con familia y amigos.
Tempranamente, a la estudiante de contemporáneo o tango escénico se le enseña la importancia abandonar, postergar o renunciar a otros aspectos de su vida personal para dedicar la mayor cantidad de tiempo, dinero y energía disponible a una formación que, además, es permanente ${ }^{8}$ : nunca se deja de aprender a bailar.

Además, llegar a ser una profesional de la danza requiere de un entrenamiento físico riguroso y exigente. En este proceso se asimila, en muchos de los casos relevados, que para tener una carrera artística exitosa -es decir, poder moverse de un trabajo artístico a otro, que debe ser cada vez más importante en términos simbólicos o estar mejor remunerado-, hay que disponerse a enfrentar muchos sacrificios: "no tener plata", "pagar el derecho de piso", "trabajar ad-honorem", "hacer cosas que no te gustan", "postergar" o "renunciar" a otros deseos y proyectos personales, etcétera.

8 La cuestión de la formación permanente en la danza contemporánea ha sido ampliamente problematizada por Mariana Sáez (2017) 
Los entrenamientos físicos también suelen ser interpretados en términos de sacrificio y rigurosidad: "hay que esforzarse", "darlo todo", "practicar hasta el agotamiento", "terminar exhausta", "quedar rota", "tomar clases todos los días de varias técnicas", "ser la mejor versión de una misma", "ensayar sin parar", "seguir una dieta adecuada y saludable", "sobreponerse al cansancio", "no abandonar", "trabajar duro", "conocerse de memoria", "exigirse siempre un poco más", "correr el propio límite", etcétera.

Estas representaciones del sacrificio se intersectan tempranamente con la noción de flexibilidad en los procesos de formación del carácter de las bailarinas, dando lugar al desarrollo de dinámicas laborales específicas, que se entraman con la moralidad compartida en estos circuitos. Sacrificio y flexibilidad forman, en definitiva, tanto el carácter como la trayectoria laboral de muchas bailarinas y se articulan, de diferentes modos y en diversos grados, en sus vidas cotidianas. Si bien es cierto que son cualidades sumamente interdependientes en la práctica y que dialogan de un modo permanente en la ejecución del movimiento, resulta útil pensarlas por separado. En la formación del carácter de un bailarín o bailarina profesional, la disponibilidad corporal puede pensarse más asociada a la noción de flexibilidad -en términos de plasticidad, fluctuación y adaptabilidad - y la fuerza, a la noción de sacrificio en términos de disciplina, esfuerzo, tenacidad, control y voluntad $^{9}-$ (Verdenelli, 2020).

Ahora bien, en cualquiera de los dos circuitos dancísticos estudiados a las mujeres se les suele exigir mayor sacrificio y flexibilidad en comparación con sus pares varones. Primero, porque se supone que las mujeres son "naturalmente" más flexibles que los varones.

Segundo, porque al ser mayoría tienen que esforzarse más, ser más creativas o tener conductas aún más flexibles y sacrificadas que sus colegas varones para poder insertarse exitosamente en estos circuitos culturales. Tercero, porque sobre los cuerpos de las mujeres suelen recaer cánones estéticos mucho más exigentes que sobre los de los varones.

Es cierto que en la danza contemporánea los cuerpos suelen ser menos generizados y más atléticos en comparación con el tango, por lo que la desigualdad genérica está basada principalmente en la diferencia numérica: la escasez de varones hace que sean mucho más valorados, en promedio, que sus pares mujeres ${ }^{10}$. Ellos suelen encontrar menos exigencias, mayor acceso, más reconocimiento y mayor legitimización en menos tiempo. Tienen, en definitiva, muchas más posibilidades de éxito profesional que sus pares mujeres solo por ser varones. Esto lleva a que los requisitos también sean mayores para las mujeres dentro del circuito contemporáneo y que muchas veces, para poder sobresalir, tengan que hacer gala de cuerpos mejor entrenados, más flexibles, virtuosos o inusuales que sus colegas varones.

Al conversar sobre sus procesos de formación, muchas bailarinas hacían hincapié en un sinfín de anécdotas que destacaban el gran esfuerzo - físico, económico, emocional y familiar - que realizaron para conseguir aquello que tanto deseaban: convertirse en bailarinas profesionales. No poder dormir lo suficiente, no disponer de tiempo de ocio, no lograr mantener una vida social por fuera de los espacios de entrenamiento, dar por terminada una relación amorosa porque era incompatible con su estilo de vida, invertir todo su dinero en tomar clases de diferentes técnicas de movimiento o postergar el deseo de ser madre, eran solo algunos de los múltiples esfuerzos que estas bailarinas destacaban en sus relatos.

Dentro de los comentarios que anoté en mi cuaderno de campo, pueden mencionarse: "mis amigas de la escuela dejaron de invitarme porque yo siempre decía que no", "llegaba a casa y mi novio se levantaba para ir a la oficina. A veces no nos cruzábamos en toda la semana", "durante la semana dormía tres horas por día", "llegaba de la milonga y al ratito sonaba el despertador para ir al trabajo", "hacía tiempo que tenía ganas de ser mamá, pero sabía que primero tenía que ganarme mi lugar bailando", "ensayaba y entrenaba todo el día, sin parar, hasta que me lesioné la rodilla", "antes de ir a una audición me mataba de hambre", "empecé la carrera re grande, como a los veinte años, sabía que tenía que trabajar muy duro para llegar", "tomaba clases todos los días de varias cosas, me reventaba", "bailaba todo el día y comía mal, salteaba comidas", "ensayaba sin parar, imaginate que mi descanso era ir a la milonga".

Henri Hubert y Marcel Mauss (1899) fueron pioneros en reflexionar sobre el concepto de sacrificio desde las ciencias sociales. Estos autores argumentan que todo sacrificio implica una consagración, dado que 
todo objeto que pasa del dominio común al dominio religioso es con-sagrado. No obstante, advierten que no debemos confundir ambas nociones y que no todas las consagraciones son de la misma naturaleza: algunas agotan sus efectos en el objeto consagrado, cualquiera que este sea, mientras que en el sacrificio la consagración irradia más allá de la cosa consagrada y alcanza a la persona moral que desea y provoca ese efecto.

En sus palabras, el sacrificio "es un acto religioso que, por la consagración de una víctima, modifica el estado de la persona moral que lo realiza o de determinados objetos por los cuales dicha persona se interesa" (1899: 155). Según Hubert y Mauss, la entrada al sacrificio, su fase inicial, se constituye de modo que la persona pueda cambiar su estado y pasar de lo profano a lo sagrado. “Para ello son necesarios los ritos que los introduzcan en el mundo sagrado y los vinculen a él más o menos profundamente, de acuerdo con la importancia del papel que han de representar seguidamente" (1899: 162).

En su estudio sobre boxeadores de un gueto negro de Chicago, Loïc Wacquant (2006) observa que la moral de los boxeadores puede resumirse en una sola palabra: sacrificio. Analiza que el sacrificio es omnipresente en los boxeadores y que rige su conducta a partir de un conjunto de normas imprecisas, aprendidas y desplegadas dentro de la misma práctica. El autor concluye que el sacrificio - tanto la idea como las prácticas reguladas que prescribe - se filtra e inunda toda la vida de los boxeadores — dentro y fuera del gimnasio-, elevándolos y colocándolos en un universo moral y sensual especial.

Siguiendo el razonamiento propuesto por estos autores, observo que para algunas bailarinas incluidas en mi estudio la idea de artista consagrada implicaba una capacidad de darlo todo de sí mismas que las colocaba en un universo moral superior al resto de las personas y las distanciaba de lo profano.

Así, el sacrificio en la danza aparecía directamente vinculado a la noción romántica de artista, es decir: se refería a una persona que era capaz de renunciar a todo -incluso, al usufructo económico- por su vocación. Se generaba una relación de superioridad moral que se construía sobre los cimientos de la entrega desinteresada. Un sacrificio que tenía la capacidad de volver sagrado lo profano y que ubicaba al arte como una esfera autónoma y diferencial, difícilmente representada como trabajo.
Para estas bailarinas, la capacidad de entregarse por completo a la profesión ofrecía una recompensa moral: las convertía en mejores personas, en seres más completos, felices y creativos. En este aspecto, el sacrificio también implicaba un proceso de conocimiento personal y era valorado positivamente por muchas artistas; dado que les indicaba — tanto a ellas mismas como a los demás - la profundidad de su compromiso y amor por la danza.

Al igual que en los boxeadores estudiados por Wacquant, el sacrificio no solo colocaba a estas bailarinas en un universo moral superior, sino que también se constituía en la fórmula mágica que les abriría las puertas del éxito. Era, en resumidas cuentas, "al mismo tiempo medio y fin, obligación vital y misión orgullosa, exigencia práctica y obsesión etológica" (2006: 140).

Claro que el sacrificio experimentado por las bailarinas de contemporáneo o por las bailarinas de tango no es igual al experimentado por las bailarinas de ballet. De hecho, la danza contemporánea se construyó, desde sus orígenes, en las antípodas de las narrativas sobre lo femenino y lo masculino que dominaban el mundo del ballet.

La técnica contemporánea abandonó la configuración de un modelo exclusivo y único de cuerpo generizado, con determinadas condiciones anatómicas exigidas para las mujeres —entre ellas: figura delgada y etérea, brazos y piernas estilizados, relación armoniosa entre el torso y las extremidades, cuello largo, cabeza pequeña, máxima elongación y apertura, empeines flexibles para arquear los pies a la perfección-; que servían para adecuarse a los movimientos y a la estética requeridos por la técnica clásica (Mora, 2011).

En cambio, el movimiento contemporáneo se fue desarrollando a partir de nuevos principios técnicos que pusieron en valor la diversidad de las formas físicas y la expresión de la singularidad de cada intérprete (Osswald, 2015; Sáez, 2017). Comenzó a postularse, así, la idea de que hay tantas formas de bailar como personas y la noción de que la única danza que existe es la de cada uno.

Si las técnicas contemporáneas son, ante todo, instrumentos de conocimiento que llevan al bailarín, o a la bailarina, a descubrir su singularidad, el crecimiento artístico dentro de estos circuitos está directamente ligado al esfuerzo, la entrega, la resistencia, la búsqueda y la determinación individual. De este modo, el reconocimiento simbólico y la legitimación entre pares 


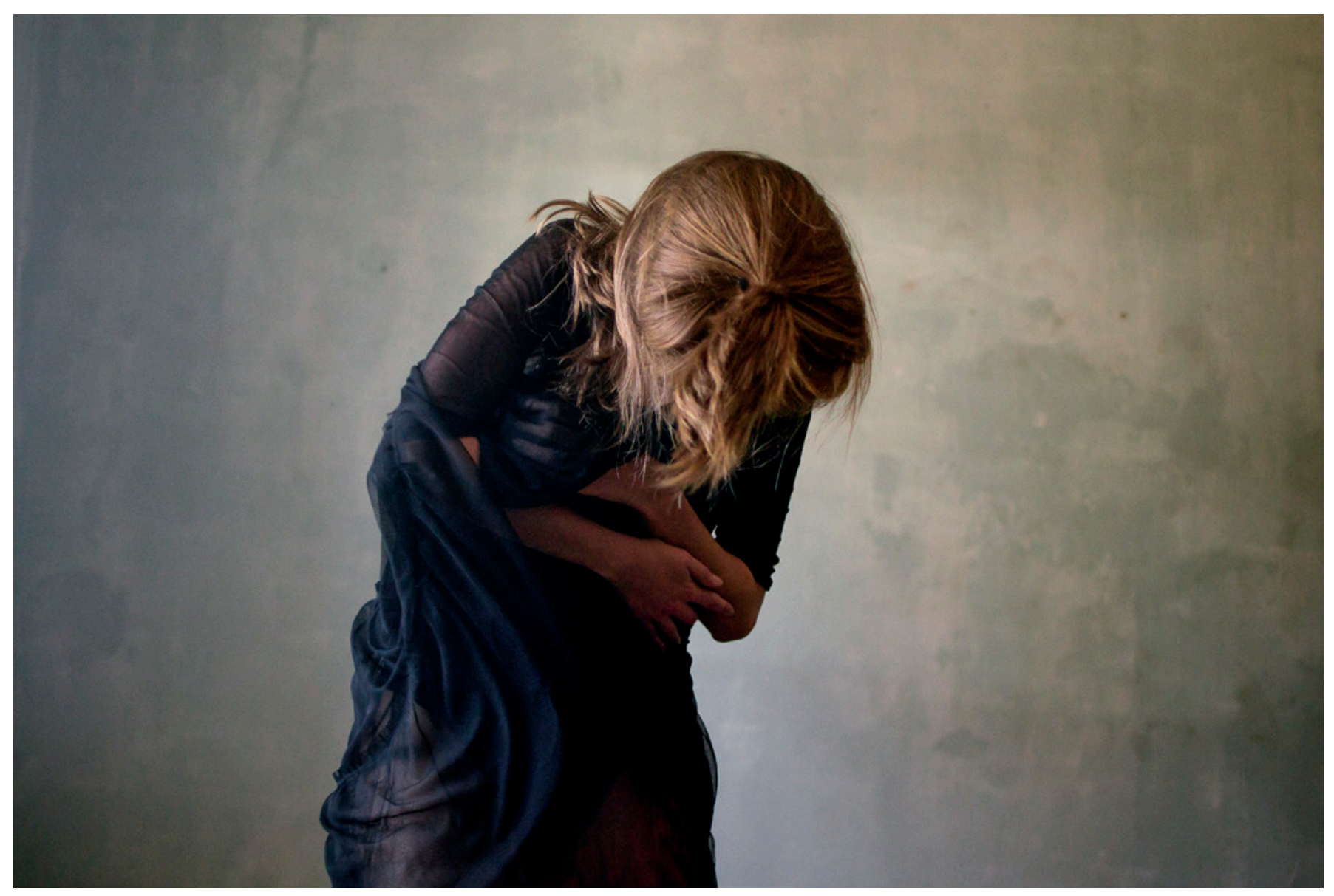

Imagen 3. Sofía Pascualetti (2020). ¿Para qué bailo?

dependen, en gran medida, del sacrificio personal. Estas bailarinas deben consagrarse a la búsqueda de la originalidad, la autenticidad, la innovación, el lenguaje propio, la singularidad, etcétera.

Marina es una bailarina de contemporáneo. Tiene 37 años y una hija de 4 . Me cuenta sobre un punto de inflexión en su carrera profesional vinculado a la autoexigencia permanente:

Yo no me daba cuenta de como exponía mi cuerpo. A veces una naturaliza correr los límites, tratar de dar siempre un poco más. A mí me gustaba mucho desafiarme, sentir que lo dejaba todo, ponerme en un lugar peligroso. Pero bueno, cuando me rompí los ligamentos cruzados me asusté mucho. Pensé que ya no iba a poder bailar más. Fue un momento muy duro para mí, la pasé mal. La operación de rodilla me obligó a parar de bailar como por un año. Hoy casi que lo agradezco, porque en ese tiempo cambié. Reflexioné mucho sobre mi forma de trabajar y aprendí a relacionarme con mi cuerpo de otra manera, con otra amabilidad, otra escucha (Marina, 37 años).

El sacrificio de las bailarinas de tango escénico, por su parte, tiene mucho perfume a milonguita ${ }^{11}$. Como representantes de la "baja cultura" y de un baile de origen popular, a muchas de estas mujeres se las acusa de hacer una carrera en el tango como un "premio consuelo" por no haber podido hacer una carrera "de verdad" en la danza clásica o en la danza contemporánea, emblemas por excelencia de la "alta cultura" aunque las bailarinas contemporáneas también suelen ser miradas con recelo por las clásicas por su falta de ascetismo, precisión y rigurosidad-. Así, los sacrificios de las bailarinas de tango suelen estar asociados a tener que vender su erotismo y sensualidad (vinculadas a un tipo de deseo heterosexual), a tener que trabajar por la noche o a ser un "entretenimiento" para el turismo internacional.

11 Figura femenina muy relevante en las composiciones musicales de las primeras dos décadas del siglo XX. Es una mujer joven, soltera, de sectores populares y "perdida moralmente" por culpa del baile del tango y los lujos del cabaret. 
Romina es una bailarina de tango de 39 años. Tiene un hijo de 3 años y una hija de 6 . Me cuenta sobre su experiencia de bailar durante muchos años para turistas extranjeros:

Yo me entusiasmé cuando empecé a ganar plata. Tenía 24 años y me pagaban recontra bien por bailar. Empecé a agarrar mucho laburo en casas de tango y terminé dejando el IUNA, porque la verdad que trabajar a la noche me complicó mucho la cursada. Se me hizo difícil y largué. Ojo, no me quejo para nada. Gracias al tango yo viajé un montón, conocí lugares hermosos que no sé si hubiese podido conocer de otra manera. Pero no sé si es que una se va poniendo más grande o qué, lo mismo que cuando era más pendeja me parecía divertido después de los 30 se volvió un garrón, lo empecé a padecer. La noche, los turistas borrachos, que cada tanto alguno te quiera levantar o se ponga cargoso, todo eso. En un momento no me banqué más el ambiente (Romina, 39 años).

Más allá de la particularidad de la consagración, las representaciones del sacrificio en la danza no parecían dejar mucho margen para un proyecto de maternidad. En las lógicas de reconocimiento y legitimación de los circuitos culturales del tango y del contemporáneo, un embarazo podía significar, por diferentes motivos, la ruina profesional.

Las giras al exterior del país, el trabajo nocturno, las condiciones laborales precarizadas, la formación permanente, el no disponer de tiempo o energía restante para otros asuntos, los múltiples trabajos en simultáneo o la exigencia de disponibilidad de tiempo completo y de flexibilidad horaria eran, entre otras, algunas de las razones que llevaban a muchas mujeres considerar que para una bailarina profesional convertirse en madre no era una opción o, en todo caso, que era un deseo personal que debía ser postergado hasta el momento en que consolidaran su carrera y ganaran su propio lugar dentro de cada circuito dancístico.

Este ideal de artista consagrada entraba en tensión, de múltiples formas, con los ideales de abnegación materna que implicaban, también, narrativas sobre el sacrificio, la entrega y la postergación de otros intereses de la vida. Si bien estos discursos no interpelaban por igual a todas las mujeres que participaron de mi investigación, las ideas de consagración con el rol de artista o de madre aparecían recurrentemente en los relatos de muchas bailarinas y movilizaban ciertos repertorios culturales que intervenían — de diferentes maneras y en distintos grados - en el universo estudiado.

Según estos modelos ideales de madre abnegada o de artista consagrada, ambas ocupaciones son profundamente incompatibles: o se es una buena madre o se es una gran bailarina. Mientras que la artista debe sacrificar todo lo demás por perseguir sus deseos e impulsos creativos, una madre ejemplar debe estar dispuesta a sacrificarse a sí misma por el bienestar de sus hijos, a renunciar a sus proyectos personales para brindarles desinteresadamente todo su tiempo, cuidados, amor y energía. Asimismo, la noción de sacrificio ligada a la idea de madre abnegada une las dos acepciones de sacrificio que vengo delineando en este trabajo: se trata de matar, cortar o hacer a un lado todo lo demás (renunciar a todo por los hijos) y, al mismo tiempo, implica una capacidad de esfuerzo sobrehumano.

Tanto en el caso de la madre como de la bailarina ideal, la palabra sacrificio involucra la postergación de otros intereses o esferas de la vida. A su vez, se espera que este sacrificio tenga una recompensa a futuro: se trata de convertirse en una gran artista o en una madre ejemplar, que dejará sus amorosas huellas en niños más seguros, confiados y felices. Aquí también opera la recompensa moral, ya que la capacidad de consagrarse y darlo todo de sí mismas convierte a estas mujeres en mejores personas, en seres más completos y las eleva moralmente por sobre el resto.

Estas representaciones hegemónicas sobre la madre y la artista exigen para sí mismas un compromiso total e intensivo, que idealmente implica renunciar a todo lo demás. En otras palabras, cuando una madre o una artista se consagran, se entregan por completo. Esta capacidad de darlo todo de sí mismas las coloca en un universo moral superior al del resto de las personas, las distancia de lo profano y las ubica en un plano trascendental de la existencia.

En los discursos de algunas bailarinas, la tensión entre esos modelos ideales aparecía como un obstáculo en sus intentos por balancear la profesión y el cuidado infantil. Si bien la mayoría de ellas manifestaba su deseo de equilibrar las demandas de su carrera con las de su maternidad, lo cierto es que muchas percibían que terminaban priorizando una esfera y postergando o descuidando la otra. Estos supuestos subyacentes salían a la luz al conversar con estas mujeres sobre las sensaciones de "tironeo" o "falta de ajuste" en sus vidas cotidianas respecto a la conciliación trabajo-familia que, en 
ocasiones, reforzaba la idea de que existía una profunda incompatibilidad entre la danza y la maternidad; manifestando una tensión entre formaciones culturales, proyectos personales y prácticas cotidianas. Para muchas de ellas, esta imposibilidad de pensarse a sí mismas en términos más flexibles y de negociar entre sus roles y proyectos como madres y bailarinas generaba diversos malestares y sentimientos de culpa.

\section{Conclusión}

En este artículo consideré que las representaciones sobre el sacrificio se intersectan tempranamente con los procesos de formación y profesionalización en el tango y en la danza contemporánea, dando lugar al desarrollo de dinámicas laborales específicas, que se entraman con la moralidad compartida en estos circuitos.

Observé que la noción de sacrificio es central para comprender los repertorios discursivos que son movilizados dentro de estos circuitos dancísticos profesionales para reivindicar un compromiso total e intensivo con el rol de bailarina y que plantean la necesidad de renunciar a la esfera personal para consagrarse a la esfera artístico-laboral. En esta línea, analicé los discursos que postulan una incompatibilidad inherente a la carrera dancística con la maternidad y que instalan la idea de que un embarazo puede significar la ruina profesional.

Concluí que este ideal de sacrificio y consagración con el rol (de bailarina o de madre) provoca sensaciones de "tironeo" en la vida cotidiana de muchas artistas respecto a la conciliación profesión-maternidad que operan de distintos modos (y en diversos grados), actualizando los modelos hegemónicos de artista consagrada y de madre abnegada.

De todas maneras, al igual que el peso simbólico (y psicológico) de la maternidad intensiva o abnegada no se traducía sistemáticamente en las prácticas de estas bailarinas, en sus posibilidades de acción y en sus dinámicas familiares —todas ellas trabajaba por lo menos medio tiempo y el modelo de cuidado infantil en los hogares tendía a ser cada vez más compartido-; el peso simbólico de la artista consagrada no significaba que, al momento de ser madres, las bailarinas de estos circuitos culturales abandonaran automáticamente la danza y, por ende, su profesión. No obstante, estas representaciones operaban en las subjetividades de muchas mujeres, potenciando sensaciones de desajuste e incompatibilidad dentro de sus proyectos personales y dotando a sus prácticas de sentidos diversos que se negociaban, se tensionaban o se confrontaban en cada contexto particular.

\section{Referencias}

Abad Carlés, A. (2012). Coreógrafas, directoras y pedagogas: la contribución de la mujer al desarrollo del ballet y los cambios de paradigmas en la transición al s. XXI. Tesis de doctorado. Departamento de Comunicación Audiovisual, Documentación e Historia del Arte. Universidad Politécnica de Valencia.

Cardús, M. E. (2015). “¿Dejarás el baile por mí?: la representación de la bailarina como trabajadora en Mujeres que bailan de Manuel Romero". Revista Culturas. Debates y perspectivas de un mundo en cambio (9), 49-65.

Clarke, M. \& Leslie E. S. (1981). Antoinette Sibley. London: Dance Books.

Crow, S. (2002). Invisible Women. Disponible en: https://tinyurl.com/6dynmhdw

Hubert, H. y Marcel, M. (1899). “De la naturaleza y de la función del sacrificio". En M. Mauss. Lo Sagrado y lo profano. Obras I. Barcelona: Barral, pp. 143-200.

Imaz, E. (2010). Convertirse en madre. Etnografía del tiempo de gestación. Madrid: Cátedra.

Mora, A. S. (2011). El cuerpo en la danza desde la antropología. Prácticas, representaciones y experiencias durante la formación en danzas clásicas, danza contemporánea y expresión corporal. Tesis doctoral en Ciencias Naturales, orientación Antropología, Universidad Nacional de La Plata.

Morris, G. (2015). "Fixed and Immutable: Ballet and Power From The Red Shoes to Black Swan". Contribution to conference. Centre for Dance Research, University of Roehampton, 1-10.

Osswald, D. (2015). “Deshacer los hábitos bailando: concepciones alternativas del cuerpo en la transmisión dancística independiente en Buenos Aires". En Carozzi, M. J. (coord.) Escribir las danzas. Coreografías de las ciencias sociales. Buenos Aires: Gorla, pp. 207-237. 
Sáez, M. L. (2017). Presencias, riesgos e intensidades. Un abordaje socio-antropológico sobre y desde el cuerpo en los procesos de formación de acróbatas y bailarines/as de danza contemporánea en la ciudad de La Plata. Tesis de doctorado, Facultad de Filosofía y Letras, Universidad de Buenos Aires.

Tharp, T. (1992). Push Comes to Shove. New York:

Bantham Books.

Verdenelli, J. (2020). Entre crear y criar: balances entre la profesión y la maternidad de bailarinas de tango y bailarinas de contemporáneo en Buenos Aires. Tesis de Doctorado en Antropología Social. Instituto de Altos Estudios Sociales, Universidad Nacional de San Martín.

Wacquant, L. (2006). Entre las cuerdas. Cuadernos de un aprendiz de boxeador. Buenos Aires: Siglo XXI Editores. 